\title{
O "messias" negro? Arlindo Veiga dos Santos (1902-1978)

\author{
"Viva a nova monarquia brasileira; \\ Viva Dom Pedro III !"1
}

\author{
The black "messiah"? \\ Arlindo Veiga dos Santos (1902-1978) \\ "Hurrah to the new Brazilian monarchy; \\ Hurrah to Dom Pedro III !"

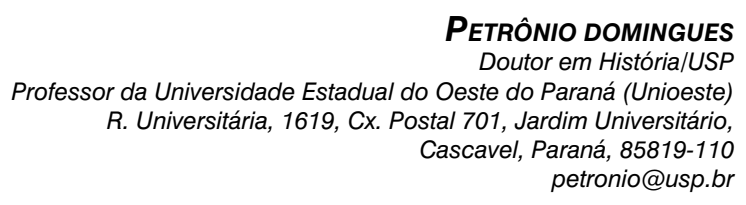

\begin{abstract}
O sindicalismo, na acepção de Veiga dos Santos, tinha uma natureza corporativa, por isso apregoava o corporativismo no meio negro. Dentro deste espírito, ele incentivava a união dos negros na FNB, tanto na aquisição de terreno quanto na construção da casa própria, pelo sistema de mutirão. No Império Patrianovista, entretanto, quem não tivesse uma "profissão ou função qualquer" seria "desclassificado: vadio não tem direito nenhum" (O Comando Patrianovista, Jan. de 1934, p.3).

Racismo, supremacismo do branco, preconceito de cor e discriminação racial compõem o fator raça, a primeira contradição para as massas de origem africana na sociedade brasileira (...). A esta se juntam outras, como a contradição de classes e de sexo. (Abdias do Nascimento).
\end{abstract}

\footnotetext{
Artigo recebido em 21/12/2005. Aprovado em 17/03/2006.

1 Agradeço a leitura atenta e os comentários de Marcos Cesaretti e da Prof. Dra. Teresa Malatian.
} 
RESUMO A proposta deste artigo é fazer breves apontamentos acerca da biografia pessoal, política e intelectual de Arlindo Veiga dos Santos (1902-78), uma das principais lideranças negras na primeira metade do século XX. Abordaremos centralmente seu ativismo político e postulados ideológicos à frente do movimento negro e monarquista, consubstanciado pela Frente Negra Brasileira (1931-37) e Ação Imperial Patrianovista Brasileira (1932-37;1945-64), respectivamente. Para finalizar, ventilamos a hipótese de que Veiga dos Santos reifica a tradição de um setor da população negra brasileira manter, no período republicano, simpatia pela monarquia.

Palavras-chave relações raciais, movimento negro e monarquista

ABSTRACT The proposal of this article is to make briefs commentaries concerning the personal, politics and intellectual biography of Arlindo Veiga dos Santos (1902-78), one of the main black leaderships in the first half of the $20^{\text {th }}$ century. First, it is supposed to approach his political fight and ideological postulates in front of the black and monarchist movement, helped by the Frente Negra Brasileira (1931-37) and the Ação Imperial Patrianovista Brasileira (1932-37;1945-64), respectively. Later, we ventilate the hypothesis that Veiga dos Santos quotes the tradition that part of the Brazilian black population seems to keep in the republican period, affection for the monarchy.

Key words racial relations, black and monarchist movement.

\section{Introdução}

Patrícios!

Matemos a república, antes que a república mate o Brasil!

Estamos entre duas revoluções: a revolução da ordem e a revolução da anarquia!

Guips do III Império! A postos!

(...) Que nos importa a república? Merece, essa criminosa, carinho algum dos Brasileiros! Vendeu-os, empobreceu-os, desmoralizou-os, anarquizou-os, fê-los miseráveis e desgraçados em 40 anos, sob a cor mentida do "progresso"!

Morra a república!!!

Que é que se espera mais do liberalismo?

Que é que se espera da sua última manifestação paroleira no Brasil - a constituinte republicana?

A gente de São Paulo que, por mal dos seus pecados e por injunções secretas, entrou sinceramente na aventura da constitucionalização (falo da gente humilde e não-politiqueira, a qual não obedece aos estrangeiros e aos patrões ocultos judeo-maçônicos que sabem o quanto Ihes rendem as "constituições"!) está descrente daquela brincadeira. 
Faliu a república.

Ela matará o Brasil, se nós a não matarmos antes!²

Por que Arlindo Veiga dos Santos, um negro, "chefe geral patrianovista", defensor da "religião, pátria e raça", em plena década de 1930, escreveria e distribuiria um boletim vociferando tanta aversão à forma de governo republicana? Será que, em última instância, ele esteja culpando a república ou a democracia constitucional por todos os problemas que passaram a enfrentar seus "patrícios", dentre os quais os ex-escravos e seus descendentes no pós-abolição? Será que seu discurso, portanto, transparece algum tipo de ressentimento racial travestido de revolta política? Trata-se de um negro que, por ventura, dirigiria alguma organização fascista, tão em voga naquele período? Ou simplesmente trata-se de mais um líder negro saudosista do sistema monarquista, debelado em 1889? Não temos ainda a resposta definitiva, porém abordaremos essas e outras questões no decorrer deste artigo.

Arlindo Veiga dos Santos foi uma das maiores lideranças da população negra na primeira metade do século XX, respeitado, inclusive, pela elite intelectual branca. Presidiu a maior entidade negra na história do país, a Frente Negra Brasileira (1931-1937). Aliado à luta política anti-racista, Veiga dos Santos desenvolveu uma ativa produção intelectual. Presidiu, também, a Ação Imperial Patrianovista Brasileira, uma organização monarquista que teve inserção em vários estados do país. Santos teve uma trajetória de vida pautada pela perseverança e abnegação. Mas, afinal, quem foi essa "legenda"?

\section{Um personagem desconhecido dos anais da história}

Arlindo Veiga dos Santos ainda é um líder negro razoavelmente desconhecido dos anais da história. Na nossa avaliação, este dado é um indicador do quanto a produção acadêmica no Brasil não preza pela diversidade racial e permanece preterindo ou escamoteando alguns personagens negros. Em ínfimas pesquisas, Veiga dos Santos é objeto de uma investigação histórica ou sociológica.

A pesquisa pioneira a desvendar uma das facetas de Santos foi a dissertação de mestrado A Ação Imperial Patrianovista Brasileira, de Teresa Maria Malatian Roy. Embora a proposta do trabalho seja, fundamentalmente, reconstruir a história e dilemas da organização política que serve de título da pesquisa, em alguns momentos a autora tece considerações acerca do seu

2 O Comando Patrianovista. Boletim pessoal do chefe geral patrianovista Arlindo Veiga dos Santos, n.2, janeiro de 1934, p.1. Em todas as citações de documentos foi respeitado o português da época, preservando-se, desta maneira, o original. 
fundador, Arlindo Veiga dos Santos, cujo pensamento foi influenciado pelo catolicismo conservador, "integralismo Lusitanto e os estudos de História do Brasil" (Malatian Roy,1978: 48). Em pesquisa posterior, publicada com o título Império e Missão: um novo monarquismo brasileiro, Teresa Malatian aprofunda a análise do patrianovismo e revela novas facetas deste movimento monarquista, como sua vinculação às classes médias católicas antiliberais, no contexto da "reação espiritualista" dos anos 1920.

Já o trabalho Movimento Negro em São Paulo: luta e identidade, de Regina Pahim Pinto, rastreia - em seção de determinado capítulo - o programa político-ideológico encampado por Arlindo Veiga dos Santos, o patrianovismo, e dimensiona seu impacto no movimento negro de um modo geral e na Frente Negra Brasileira, em especial. Suas principais hipóteses são: primeiro, as propostas patrianovistas desse líder negro, direta ou indiretamente, influenciaram sobejamente a Frente Negra; segundo, tais propostas tinham muitos pontos em comum com as "bandeiras" do integralismo, a versão brasileira do fascismo italiano: "é possível perceber muitas afinidades entre ambos ou, pelo menos, a repercussão de muitas idéias dos líderes da Ação Integralista Brasileira nos princípios patrianovistas, defendidos por Arlindo Veiga dos Santos, tanto nas suas obras como nos seus artigos publicados na imprensa negra. Muitos princípios integralistas podem ser identificados, também, na maneira como o líder negro concebia a Frente Negra" (Pinto, 1993:129).

No livro de coletânea Dialética Radical do Brasil, Clóvis Moura destina um sucinto tópico, O intelectual negro dividido: Arlindo Veiga dos Santos, para abordar as idéias políticas e raciais deste intelectual:

adepto de uma postura independente do negro, articulador de um projeto negro - talvez o mais importante após a Abolição — (...) personificou a imagem dessa inteligentsia negra que, se de um lado sentia a discriminação social e étnica pela qual passava a comunidade negra, do outro, tinha o seu pensamento integrado em uma postura monarquista, nacionalista, católica e elitista (Moura, 1994: 193).

No entanto, o mais comum é Arlindo Veiga dos Santos ser citado obliquamente ou simplesmente ser tematizado em um único parágrafo. Deste caso, podemos mencionar a pesquisa Negros e brancos em São Paulo (1888-1988), de George Reid Andrews (1998: 230):

Um dos participantes de maior destaque da vida cívica negra em São Paulo durante a década de 1920, e freqüente colaborador da imprensa negra, foi Arlindo Veiga dos Santos, um migrante da Bahia que trabalhava como secretário da Faculdade de Direito e jornalista em tempo parcial. Dos Santos trabalhou com José Correia Leite e Jayme Aguiar em seus esforços para organizar o Congresso da Juventude Negra, e também foi presidente do Centro Cívico Palmares. 
Lamentavelmente, o único parágrafo que George Andrews reserva para enfocar o nosso personagem é marcado por imprecisões. Primeiro, porque Veiga dos Santos não era migrante da Bahia, mas paulista, proveniente da cidade de Itu; segundo, porque jamais trabalhou como secretário da Faculdade de Direito. A única faculdade de Direito que existia em São Paulo na época, a do largo do São Francisco, era pública e Santos, por questão de princípio, sempre recusou cargos públicos. Na década de 1930, rejeitou o convite para assumir a secretaria da Educação do Estado de São Paulo, alegando que não se beneficiaria do "presunto republicano". ${ }^{3}$ Por isso, só trabalhou em instituições privadas de ensino. E, finalmente, pelo que consta, ele nunca foi presidente do Centro Cívico Palmares (1926-1929), conceituada entidade negra que existiu em São Paulo.

\section{Arlindo Veigas dos Santos e o movimento monarquista}

No dia 12 de fevereiro de 1902, nascia Arlindo José da Veiga Cabral dos Santos na cidade de Itu, interior de São Paulo. De origem humilde, iniciou naquela cidade seus estudos, em escolas católicas. Ainda adolescente, revelou talento literário e jornalístico, tanto escrevendo poesias quanto colaborando em algumas publicações locais. Por problemas financeiros da família, transferiu-se para São Paulo, onde fez curso universitário na Faculdade de Filosofia e Letras de São Paulo (que se tornaria futuramente a Faculdade São Bento). Nesta instituição, concluiu o curso de Filosofia e Letras, em 1926. Destacou-se precocemente na vida acadêmica, tornandose colaborador da revista Filosofia daquela instituição.

A religião influenciou imensamente a formação ideológica de Veiga dos Santos. Desde a mais tenra idade, esteve ligado ao catolicismo praticante. Quando se mudou para São Paulo, filiou-se à Congregação Mariana da Imaculada Conceição de Santa Ifigência. Foi um carola mariano muito aplicado, a ponto de ter chegado à presidência dessa irmandade, em 1940. Levava uma vida ascética, freqüentando assiduamente o culto, "fazendo do jejum e da penitência hábitos constantes" (Malatian Roy, 2001: 46). Veiga dos Santos colaborou ou dirigiu alguns jornais católicos, entre os quais $O$ Mensageiro da Paz e O Século. Ele também foi membro do Centro D. Vital de São Paulo, ligado à revista "A Ordem", periódico de orientação ultraconservadora que congregava os intelectuais católicos, dentre os quais o proeminente Jackson de Figueiredo.

Em 3 de março de 1928, em conjunto com alguns amigos, Veiga dos Santos fundou o Centro Monarquista de Cultura Social e Política Pátria-Nova (CMCSP Pátria Nova). Nesse período, Santos já havia estabelecido as ba-

3 Entrevista de Regina Pahim Pinto com Francisco Lucrécio, 23.05.1989, p.34. 
ses do programa político-filosófico-religioso de construção da Pátria-Nova, fundada no princípio de que a instauração do III Império seria a salvação para todos problemas do Brasil. Encontramos um artigo publicado no jornal da imprensa negra, ${ }^{4}$ em que Arlindo Veiga dos Santos já expõe o mote de seu pensamento: "A grande obra da ação negra no Brasil deve começar pela família pois que é ela a célula-mãe de toda a sociedade civil. É a família a união do varão e a esposa com seus filhos, debaixo do governo do varão. É ela o protótipo da sociedade política ou estado mais perfeito, isto é - monarquia". ${ }^{5}$

Veiga dos Santos era "inclinado a profecias, predestinações, premonições, símiles evangélicas, julgava-se inspirado por Deus e dotado de carisma. Acreditava que ao completar 33 anos lhe aconteceria algo muito importante" (Carta de A. Paim Vieira, São Paulo, 17/2/1977 apud Malatian Roy,1978: 51). Daí provavelmente seu estilo messiânico. Ainda paira certo mistério sobre sua personalidade e vida pessoal. Conforme depoimento de Raul Joviano do Amaral - um companheiro de militância no movimento negro - ele, nessa época, "só tinha uma calça e um paletó, um sapato desbeiçado". Passava privações materiais e tinha até dificuldade de alimentação. ${ }^{6}$ Iniciava e encerrava as reuniões do CMCSP Pátria Nova com uma oração, e frisava que o próprio movimento de defesa do III Império nasceu "sob a inspiração da Santíssima Trindade". Em 1932, essa organização reformou os estatutos e se transformou em Ação Imperial Patrianovista Brasileira (AIPB). Apesar da contribuição importante dada por seus companheiros, Veiga dos Santos foi o responsável pela criação do movimento patrianovista, "tanto no referente ao programa como aos estatutos do Centro Monarquista de Cultura Social e Política e da Ação Imperial Patrianovista Brasileira" (Malatian Roy,1978:65). Eis o programa do patrianovismo:

I - CREDO - Privilégio do Catolicismo, Religião obrigatória nas escolas públicas, nos quartéis, institutos hospitalares e correcionais, etc.

II - MONARQUIA - Imperador responsável que reine e governe, escolhendo livremente os seus ministros. Base municipal sindicalista da organização do Estado Imperial. Direitos magestáticos da Dinastia Nacional, aclamada pela Nação no fundador político da Pátria Imperial Brasileira D. Pedro I, e agora representada por S. A. I. Dom Pedro Henrique.

III - PÁTRIA E RAÇA BRASILEIRA - Afirmação da Pátria Imperial Brasileira; sua valorização espiritual (religiosa, intelectual e moral), física e econômica. Afirmação da Raça Brasileira em todos os seus elementos tradicionais e novos integrados (filhos de estrangeiros). Solução séria e definitiva do problema negro-índio-sertanejo. Formação e valorização física, intelectual e religioso-moral nacionalista da Raça Brasileira. Definição da situação do estrangeiro dentro do Império instaurado. Reação contra todas as formas de imperialismo estrangeiro no Brasil.

4 Imprensa negra é uma referência aos jornais produzidos por negros e dirigidos à comunidade negra em São Paulo no início do século XX (Ferrara, 1986).

5 O Clarim d Alvorada. São Paulo, 13.05.1927, p.3.

6 Entrevista de Raul Joviano do Amaral a Ana Lúcia Valente e João Batista Borges Pereira., s/d, p.8.

\section{2}


IV - NOVA DIVISÂO ADMINISTRATIVA - Divisão do País em províncias menores, puramente administrativas. Educação obrigatória especial contra o espírito regionalista e intensificação do amor à cidade natal ou município, célula da Pátria Imperial. Capital no centro do Império.

V - ORGANIZAÇÃO SINDICAL das classes profissionais de produção espiritual (religiosa, moral e intelectual) e econômica: clero, magistério, artes liberais, artes mecânicas, agricultura, comércio e indústria nacionais, e outras, com base da verdadeira representação nacional.

$\mathrm{VI}$ - CAPITAL NO CENTRO DO IMPÉRIO.

VII - POLÍTICA INTERNACIONAL ALTIVA E CRISTÃ.

VIII - ENTENDIMENTO ESPECIAL IBERO-AMERICANISTA (Revista Pátria-Nova. São Paulo, 09/1929).

Em panfleto escrito por Arlindo Veiga dos Santos, ficava expresso, de maneira concisa, a ideologia do movimento do qual foi aclamado Chefe Geral:

Somos Pátria-Nova, extrema direita radical e violenta, afirmadores de Deus e sua Igreja, afirmadores da Pátria Imperial e Católica, inimigos irreconciliáveis e intolerantes do burguesismo, plutocratismo e capitalismo materialista, ateu, gozador, explorador, internacionalista, judaízante e maçonizante; inimigos da república, dos partidos, do parlamentarismo, em suma do liberalismo religioso, político e econômico; enfim, tão inimigos também da anarquia bolchevista que com erros igualmente grandes pretende em vão "corrigir" a tirania da burguesia liberal, como inimigos da ordem social mentirosa, instalada em quase todo o mundo ${ }^{?}$

Arlindo Veiga dos Santos era, antes de mais nada, um negro reacionário, na medida em que buscava anular as forças progressistas da história e inverter a tendência de modernização da sociedade brasileira, lutando pelo restabelecimento de uma ordem política e social obsoleta. Era nacionalista xenófobo e anti-semita fervoroso. No seu discurso, o judeu era descrito como um explorador que sempre aparecia associado à burguesia internacional, às finanças, à usura, à encarnação dos interesses alienígenas. Nos seus escritos políticos, ele constantemente evocava o suposto complô judaico-maçônico.

Descrente nas instituições da democracia liberal, culpava o capitalismo imperialista, a ação dos judeus e da maçonaria, de um lado, e os comunistas, de outro, pelas mazelas da sociedade brasileira de um modo geral e, dos negros, em particular. Rechaçava radicalmente o parlamento e as eleições, atribuindo-lhes uma das causas da "desordem, desorganização e ruína" do Brasil. Igualmente, abominava os partidos políticos, considerados nefastos porque representavam várias facções; logo, atentavam contra a unidade

7 O Clarim de Pátria-Nova. São Paulo, s/d. 
nacional. Na sua concepção, a solução para as mazelas do país, tais como: a desonestidade, a imoralidade, os erros políticos, econômicos, a inflação, a impunidade, só dependia de uma solução totalitária: a instauração de um Estado orgânico neo-monarquista dotado de um governo forte.

Quanto ao seu anticomunismo, vale assinalar que, entre 1932 e 1933, Veiga dos Santos já havia integrado em São Paulo a efêmera "Liga contra o Comunismo". ${ }^{8}$ Similarmente, não podemos minimizar o papel do espiritualismo cristão em seu pensamento. Este, aliás, é um dos motivos pelos quais repudiava todas ideologias liberais, democráticas ou suas pretensas filhas comunistas. Para esse líder negro, tais ideologias, por natureza, afrontavam a Soberania Divina, ou seja, contrariavam a realização do "Cristo Total" ou a existência do corpo místico, que só poderia ser alcançado pela fidelidade absoluta à fé (Pinto, 1993:134).

As publicações doutrinárias do movimento patrianovista foram diversas. Em 1929, ainda quando a entidade denominava-se Centro Monarquista de Cultura Social e Política Pátria-Nova, lançou-se o primeiro número da revista Pátria-Nova, trazendo como subtítulo Religião, Pátria e Raça. Em 1933, foi fundado o Boletim Pátria-Nova, suplemento mensal da revista, dirigido por Veiga dos Santos e Paulo Dutra da Silva. No mesmo ano, Veiga dos Santos, afirmando seu personalismo, resolveu publicar O Comando Personalista, boletim pessoal do chefe-fundador do movimento:

Este Boletim é grito de guerra, de combate; é ação reivindicatória dos direitos que tem a Pátria Brasileira de ser Imperial, de ser Católica, é ação acusatória chamando a contas a Ré...pública, o liberalismo, a democracia; é o libelo franco e decidido contra a Anti-Nação, constituída pelo judaísmo, maçonismo, comunismo... . ${ }^{9}$

Em 1932, foi criada a Guarda Imperial Patrianovista (GUIP), um grupo paramilitar voltado para defender o movimento dos ataques dos "comunistas", proteger o "Brasil-Cristão" e "preparar a instauração do III Império". A maior parte dos milicianos era jovem e ficava contagiada com a pregação envolvente de Veiga dos Santos, exortando, inclusive, o uso das armas: "precisamos lutar violentamente, pela pena, pela palavra e pelas armas", contra o "brasilzinho ridículo liberal-judeo-maçônico-republicano e traidor". ${ }^{10}$ Tanto os milicianos como os demais patrianovistas usavam a saudação "Glória!", proferida de maneira imponente, acompanhada de um gesto: o braço direito levemente estendido, com os dedos polegar, indicador e

8 Carta de 31 de janeiro de 1936. Prontuário no. 2018, Isaltino Veiga dos Santos. Arquivo DEOPS.

9 Boletim Pátria-Nova. São Paulo, julho/agosto de 1933.

10 O Comando Patrianovista. Boletim pessoal do Chefe-Geral Patrianovista Arlindo Veiga dos Santos. Dezembro de 1933, p.6. 
médio levantados (Malatian Roy,1978:127). O termo era uma abreviação do "Glória à Santíssima Trindade!".

No auge do movimento patrianovista, especulou-se que o herdeiro presuntivo do trono brasileiro, D. Pedro Henrique de Orleans e Bragança, confabulava nos meios monarquistas. ${ }^{11}$ A Casa de Bragança chegou a manter contato com o chefe geral patrianovista, conforme a carta do próprio D. Pedro Henrique: "agradeço ao ilustre Dr. Veiga dos Santos e aos seus valorosos colaboradores o inestimável serviço prestado ao Brasil e à Monarquia, estudando e organizando o plano da 'Orgânica', sob cuja bandeira por sem dúvida se unirão todos quantos almejam ver instalados no Brasil o regime da liberdade, de justiça, de honestidade, que fez, no passado, a grandeza de nossa terra e que, no futuro, proporcionará à nossa gente dias de paz, de concórdia, de felicidade e de progresso". ${ }^{12} \mathrm{Na}$ sua pesquisa, Malatian (Malatian Roy, 2001:135) também apresenta uma carta de D. Pedro Henrique, de 1933, aclamando simpaticamente o movimento patrianovista. Após 1945, o herdeiro presuntivo do trono brasileiro passa a residir no país e se aproxima da AIPB, realizando várias visitas à sua sede em São Paulo. Essa última autora ainda anexa à referida pesquisa algumas fotos de Arlindo Veiga dos Santos ao lado de D. Pedro Henrique.

Em 1934, Veiga dos Santos, alegando "motivos particulares", renunciou à presidência da Ação Imperial Patrianovista Brasileira. Extremamente autoritário, não tolerava nenhum tipo de indisciplina ou desrespeito à hierarquia. Apesar dessas justificativas, desconfia-se que a verdadeira causa do afastamento de Santos da chefia-geral da entidade tenha sido o racismo que sofrera dos dirigentes patrianovistas brancos (Malatina Roy, 1978:113). No entanto, ele continuou influenciando os rumos do movimento e, em 1936, reassumiu, discricionariamente, a chefia-geral da organização, em um segundo mandato.

O movimento se expandiu para mais de quinze estados do país. Entretanto, em 1937, Getúlio Vargas liderou um golpe de estado, instalou um regime ditatorial batizado de Estado Novo, e colocou todas as organizações políticas na ilegalidade. Desse modo, chegou ao fim a primeira fase do movimento patrianovista.

Quando foi fechada, segundo Alfredo Teixera de Jesus, o movimento tinha mais de "duzentos e cinqüenta mil (250.000)" adeptos. ${ }^{13}$ Tratava-se de uma estimativa demasiadamente exagerada, provavelmente com fins propagandísticos. Além dos patrianovistas jamais terem efetuado um censo interno na organização, as fontes consultadas indicam que seu movimento

11 Arquivo DEOPS. Carta encontrada no Dossiê n. 50-J-88.

12 Carta recebida em 25.09.1950 In: CIERO, Hermes di. Honra ao Mérito. São Paulo: AIPB, 1951, p.5.

13 JESUS, Alfredo Teixeira de Jesus. Boletim "Pela Monarquia". São Paulo, AIPB, 08.08.49. 
não teve inserção nas massas. Pelo contrário, não passou de um movimento nitidamente vanguardista.

Com efeito, o patrianovismo foi talvez o movimento político de ultradireita mais expressivo no Brasil antes da fundação da Ação Integralista Brasileira (AlB), em 1932. Alguns entendem que o Patrianovismo era uma combinação híbrida de fascismo com neomonarquismo católico. Havia muitas afinidades entre a AIPB e a AIB. No discurso patrianovista, o integralismo era apontado como uma proposta complementar à da Pátria-Nova (Malatian Roy, 2001:68). Plínio Salgado, o principal dirigente integralista, trocava cartas com Arlindo Veiga dos Santos e tentou o apoio dele para seu movimento, o que nunca aconteceu. ${ }^{14}$ Segundo José Carlos de Ataliba Nogueira - exintegrante da AIPB - Plínio Salgado, no início da AIB, ameaçava culpar a não adesão dos patrianovistas por um eventual malogro do integralismo no país. ${ }^{15}$ Porém, quando o integralismo se tornou movimento de massa, alguns patrianovistas - como Luís da Câmara Cascudo ${ }^{16}$ e o então padre Hélder Câmara - migraram para a AIB.

\section{Arlindo Veiga dos Santos e o movimento negro}

Um outro campo de atuação de Veiga dos Santos foi a luta pela elevação moral, política e social da população negra. Desde a década de 1920 engajou-se no movimento negro organizado, escrevendo para os jornais da "raça" e se empenhando na construção das entidades negras, como o célebre Centro Cívico Palmares. Em 16 de setembro de 1931, foi um dos fundadores e primeiro presidente da Frente Negra Brasileira (FNB). Criada em um contexto de forte ascensão do movimento negro, a FNB materializava o avanço na luta pela "união política e social da Gente Negra Nacional". Esta organização desenvolveu vários projetos, dentre os quais, uma escola noturna para jovens e adultos, da qual Veiga dos Santos foi um dos professores. Era um dos coordenadores do trabalho de doutrinação da "massa" negra, ministrando cursos, realizando palestras ou simplesmente discursando nas chamadas domingueiras.

Veiga dos Santos pretendia arregimentar os negros e as negras para a causa monarquista. Assim, a FNB constituiu-se em outro espaço de

14 Porém, não podemos esquecer de que, no início de 1932, Arlindo Veiga dos Santos é um dos fundadores — em conjunto com Plínio Salgado e outros intelectuais - da Sociedade de Estudos Políticos (SEP), o núcleo embrionário e pensante do movimento integralista (Carone: 1982). Ele permanece neste grupo até o início do segundo semestre daquele mesmo ano.

15 Entrevista de José Carlos de Ataliba Nogueira a Teresa Maria Malatian Roy, s/d, p.2.

16 Na época que era patrianovista, Luís da Câmara Cascudo escreveu um artigo no Diário de Natal, do Rio Grande do Norte, denominado "O Mestre Solitário", em que enaltece a sapiência de Arlindo Veiga dos Santos, qualificado de "doutor em filosofia", um "alto pensador", "sabotado" no nosso país por uma "autoridade invisível", mas conhecido quando se "passa a fronteira do Brasil". Este artigo foi transcrito em CIERO, Hermes di. Honra ao Mérito. São Paulo: AIPB, 1951, p.4. 
difusão das idéias patrianovistas. Esta, também, é a inferência de Teresa Malatian:

embora os militantes (patrianovistas) dispusessem de organização própria, buscavam atuar em diversos meios, nos quais pudessem divulgar o movimento e criar condições para que a exigência de instalação da monarquia se apresentasse 'espontaneamente'. Nessa estratégia se inclui a atuação dos patrianovistas junto à Frente Negra Brasileira, sobretudo com a participação de Veiga dos Santos (Malatian Roy, 2001: 54).

Ele, por exemplo, utilizava o jornal da FNB para fazer proselitismo de seu projeto político-ideológico. Mas não podemos superestimar a recepção das suas idéias no meio negro. Segundo Francisco Lucrécio - ex-dirigente da FNB - o Arlindo Veiga dos Santos orientava o negro no "sentido" nacionalista, "mas o negro não chegava a compreender o que era patrianovismo". ${ }^{17}$

De toda sorte, é possível identificar algumas semelhanças, neste período, entre o movimento da Frente Negra Brasileira e o movimento patrianovista. Ambos se posicionavam a favor do nacionalismo exacerbado, da defesa das tradições brasileiras e repudiavam o comunismo. Era comum os dirigentes da FNB fazerem ataques à democracia e ao liberalismo. Arlindo Veiga dos Santos, aproveitando o terreno fértil, articulou uma aproximação dos dois movimentos. Dois fatos, pelo menos, evidenciam essa articulação: Isaltino Veiga dos Santos, seu irmão, e Salathiel Campos eram patrianovistas que participavam ativamente das atividades da FNB. O primeiro até chegou a ser o Secretário Geral da organização. Um outro indício, ainda que residual, da tentativa de apromixação, foram as recomendações de Veiga dos Santos para que os patrianovistas freqüentassem a FNB, contratando os serviços oferecidos pelo seu gabinete dentário. ${ }^{18}$ Ele implantou no movimento negro uma filosofia análoga a que imprimiu ao patrianovismo. Por exemplo, a estrutura organizacional da FNB era verticalizada, fundada em uma rígida hierarquia e no espírito quase espartano de disciplina, nos moldes que ele projetou na Ação Imperial Patrianovista Brasileira. ${ }^{19}$

Este líder negro foi o autor do estatuto dessas duas organizações, por isso, talvez, ainda seja possível apontar outras "coincidências" entre elas: mantinham a figura do Chefe Geral, com poder altamente centralizado, auxiliado pelo Grande Conselho; destacaram alguns ativistas — os cabos distritais da FNB correspondiam aos arautados patrianovistas - para realizar o trabalho de base de construção do movimento; criaram uma milícia e adotaram uma série de sinais diacríticos (bandeira, brasão, hino). No

\footnotetext{
17 Entrevista de Francisco Lucrécio a Regina Pahim Pinto, em 23.05.1989, p.22.

18 O Comando Patrianovista. Dezembro de 1933, p.6.

19 Segundo Teresa Malatian Roy (Malatian Roy, 2001:16), o "pensamento autoritário defende uma organização hierárquica da sociedade como condição para se alcançar a ordem, entendendo que a ausência de um rígido ordenamento hierárquico fatalmente leva a sociedade ao caos e à desagregação."
} 
caso da FNB, a milícia possuía uma linha de frente composta por negros capoeristas.

Carismático e eloqüente, Veiga dos Santos conquistou a admiração dos afiliados da FNB. Em determinado panfleto de agitação, escreveu: "Meus irmãos negros! Viva a raça!". ${ }^{20}$ Centralizador e personalista, dirigiu a entidade de maneira muito autoritária. Não admitia divergência e perseguia seus adversários políticos. O regime ditatorial de governo era propalado por Santos como a melhor alternativa de condução dos "frentenegrinos", conforme escreveu: "Nada de apelar para assembléias gerais, que são contra os nossos Estatutos. Nada de quererem todos mandar! Há um Presidente Geral e um Grande Conselho. Tudo que o Presidente Geral e o G.C. fazem é para o bem de todos os Frentenegrinos e todos os negros de boa-vontade" ${ }^{21}$

Em 1933, a FNB publicou o jornal A Voz da Raça, tendo como subtítulo Deus, Pátria, Raça e Família. Esta consigna diferenciava-se da palavra de ordem dos integralistas apenas no acréscimo do termo Raça. Plínio Salgado, a principal liderança integralista, chegou a ter um de seus artigos publicado no jornal A Voz da Raça. Segundo um antigo ativista do movimento negro, Arlindo Veiga dos Santos participou do Primeiro Congresso da Ação Integralista Brasileira, ocasião na qual proferiu um discurso prometendo o apoio da Frente Negra Brasileira e de seus 200.000 negros aos integralistas (Leite \& Moreira,s/d:13). Temos dúvidas se esta informação procede, ${ }^{22} \mathrm{O}$ que sabemos, seguramente, é que $A$ Voz da Raça, como já assinalamos, foi um órgão da imprensa negra usado como instrumento propagandístico do programa ideológico patrianovista (Pinto:1993,136). Em artigo batizado de Basta de exploração!!!, Arlindo Veiga dos Santos afirmava tal programa, indicando, por exemplo, de que maneira o regime nazista alemão — em matéria de projeto nacional e política racial - devia ser transplantado para o Brasil:

Que nos importa que Hitler não queira, na sua terra, o sangue negro? Isso mostra unicamente que a Alemanha Nova se orgulha da sua raça. Nós também, nós Brasileiros, temos RAÇA. Não queremos saber de ariano. QUEREMOS O BRASILEIRO NEGRO E MESTIÇO que nunca traiu nem trairá a Nação.

Nós somos contra a importação do sangue estrangeiro que vem somente atrapalhar a vida do Brasil, a unidade da nossa Pátria, da nossa raça da nossa Língua.

20 Arquivo DEOPS. Prontuário $n^{\circ}$.1538. Documento de 04.05.1932.

21 A Voz da Raça. São Paulo, 07/07/1934, p.1.

22 Para Teresa Malatian Roy (Malatian Roy, 2001:59), a cooptação da Frente Negra pela Ação Integralista Brasileira é uma questão que permanece desconhecida, exceto por registros esparsos, como a notícia do comparecimento de Plínio Salgado em uma reunião na sede da Frente Negra em Santos, veiculada pelo jornal A Platéia, de 16 de novembro de 1932. 
Hitler afirma a raça alemã. Nós afirmamos a Raça Brasileira, sobretudo no seu elemento mais forte: O NEGRO BRASILEIRO.23

Neste excerto do artigo, Arlindo Veiga dos Santos fazia uma declaração de princípio, cuja tônica era seu nacionalismo fundamentalista. Para o presidente da Frente Negra, não importava os meios, mas apenas os fins do nazismo: a valorização racial da Alemanha. Por isso, era irrelevante se Hitler conduzia a Alemanha por métodos racistas. A aversão nazista ao "sangue negro" era avaliada como uma medida de orgulho patriótico, um gesto nacionalista, que visava, exclusivamente, proteger a raça "ariana".

O projeto nacional do regime nazista era concebido de maneira tão positiva, que, nós, brasileiros, deveríamos aplicá-lo em nosso país, pelo menos no que dizia respeito à sua ideologia racial, ou seja, tínhamos que ter uma postura anti-semita, xenófoba, sermos refratários aos "arianos" e à entrada dos imigrantes - que, afinal, colocavam em risco a unidade nacional e racial do país. Implantando um projeto nacional nos moldes nazistas, conseguiríamos valorizar o autêntico brasileiro, o negro ou mestiço. Em suma, só com uma política racial de natureza "nazista" afirmaríamos a verdadeira raça brasileira, "sobretudo no seu elemento mais forte: o negro".

Quanto ao sentimento de hostilidade por parte do movimento negro em relação ao estrangeiro, salientamos que, na nossa avaliação, foi uma reação que refletia a perda de espaço do negro no mercado de trabalho formal no pós-abolição, cada vez mais monopolizado pelos "oportunistas" ou "alienígenas" imigrantes.

Para Pinto (1993:129), "muitas das idéias defendidas pelos patrianovistas eram apregoadas através do jornal A Voz da Raça", não só por Arlindo Veiga dos Santos, "mas também por vários outros líderes negros que militavam na Frente Negra".

Em 1934, Veiga dos Santos se afastou da presidência da entidade, mas continuou defendendo uma gestão totalitária, personificada na figura do chefe. Explicando as razões pelas quais atribuía o sucesso da FNB, escrevia: "Frentenegrino obedece a uma disciplina. Há unidade de comando e todos defendem a autoridade do chefe. Ninguém discute o Chefe. Foi debaixo dessa disciplina que pudemos vencer os mais terríveis elementos da desordem soprada em nosso meio pelos elementos socialistas, isto é - comunistas". ${ }^{24}$ Com a instauração do Estado Novo, em 1937, a FNB também foi extinta.

23 SANTOS, Arlindo Veiga dos. Resposta a um boletim lançado pela canalha anarquista-comunista-socialista, que obedece aos patrões judeus e estrangeiros. Frentenegrinos! Negros em geral! A postos contra a onda estrangeira, que, além de vir tomar o nosso trabalho, ainda quer dominar, por um regime iníquo e bandalho, o Brasil dos nossos avós. In: A Voz da Raça. São Paulo, 09.12.1933, p.1.

24 A Voz da Raça. Setembro, 1936, p.1. 


\section{O fim da maior liderança monarquista negra na república}

Com a redemocratização do país, em 1945, Arlindo Veiga dos Santos relançou o movimento Patrianovista. ${ }^{25} \mathrm{~A}$ despeito de encabeçar um movimento esvaziado, passou a ser visto como figura suspeita pelo regime político vigente. Como resultado, foi vigiado pelo DEOPS (Departamento Especial de Ordem Política e Social) - a polícia política da época - e chegou a sofrer tanto intimidação como perseguição policial. Rotulado de integralista, Veiga dos Santos teve suas correspondência submetidas ao crivo da censura. ${ }^{26}$ Entre 1945 a 1964, a Orgânica Patrianovista constitui a obra básica do movimento (Malatian Roy, 2001:71). Em 1955, após a reativação da Ação Imperial Patrianovista Brasileira, publicou o jornal Monarquia. Órgão da Chefia Geral Patrianovista, trazendo em letras garrafais o seguinte slogan: "Sem Rei não há União Nacional". Neste período, continuou sua militância pastoral na igreja Nossa Senhora da Boa Morte, situada na rua do Carmo, centro de São Paulo.

Veiga dos Santos era culto, dominava várias línguas. Traduziu alguns livros. Foi professor de latim, inglês, português, história, sociologia e filosofia. Lecionou em algumas escolas particulares e faculdades como, por exemplo, na Faculdade São Bento, que se transformou posteriormente na Pontifícia Universidade Católica (PUC) de São Paulo. Na qualidade de intelectual, poeta e escritor, Veiga dos Santos é autor de diversas obras: Os filhos da Cabana, Contra a Corrente, Para a Ordem Nova, Eco do Redentor, A lírica de Luís Gama, O Problema Operário e a Justiça Social; Brasil, província de El-Rei, Sentimento de Fé, Incenso de minha miséria, Nóbrega e outros patrícios, Idéias que marcham no silêncio, Totalitários e Democráticos na Redenção social do Brasil. Em 1923, publica o livro Amar... e amor depois, que mereceu a menção honrosa da Academia Brasileira de Letras. Desperta curiosidade o opúsculo Satanás. Escrito em 1924 - quando o autor tinha 22 anos - mas só publicado em 1932, é um poema profético, "baseado num sonho tido em MCMXXII". Em 1956, foi eleito sócio titular do Instituto Histórico e Geográfico de São Paulo.

Seu talento intelectual foi reconhecido internacionalmente, recebendo uma série de diplomas honoríficos, dentre os quais merecem destaque: membro honorário vitalício, na qualidade de fellow da American International Academy, de Nova York; dignidade e honra da Estrela e Cruz de Academic Honor; membro de honra da Légion des Volsntaires du Sang, de Paris; sócio de honra da Associazione Internazionale Insigniti Ordini Cavallereschi,

25 Arquivo DEOPS. Comunicado do Serviço Secreto. Pasta n. 50-J-88. Encontramos documentos do DEOPS comprovando que Arlindo Veiga dos Santos rearticulou o movimento patrianovista no ano de 1945. Essa data, entretanto, diverge da posição de Teresa M. Malatian Roy (1978:86), que aponta 1950 como ano de reativação do movimento.

26 Arquivo DEOPS. Documento de 10.05.1945 (confidencial). Pasta n. 30-Z-0-505 
de Palermo, Itália. ${ }^{27}$ Alguns até asseguram que Veiga dos Santos era mais conhecido no exterior (Argentina, Portugal, Chile, Espanha, Cuba, França, México ou Bélgica) que em sua "pátria". 28

Já sem a mesma capacidade de mobilização dos anos iniciais, o movimento Patrianovista esboroou-se progressivamente após 1964, com o golpe militar que instalou a ditadura no país. ${ }^{29} \mathrm{Na}$ verdade, os patrianovistas foram vítimas de suas próprias ações políticas, pois, como revela Teresa Malatian Roy (2001:77), eles integravam as forças da reação que conspiraram e derrubaram o governo democrático de João Goulart, em 1964. Com o fim das liberdades democráticas, Arlindo Veiga dos Santos ficou no ostracismo político. Solteiro, levando uma vida solitária, faleceu em 1978, defendendo seus ideais monarquistas.

\section{O pensamento racial de Arlindo Veiga dos Santos}

Para Arlindo Veiga dos Santos, a monarquia corporativista patrianovista era a saída para os ex-escravos e seus descendentes superarem a exclusão na sociedade brasileira. Em artigo intitulado Os negros e o III Império, ele dissociava a imagem da monarquia brasileira do século XIX com o estatuto da escravidão e denunciava que o golpe de estado que instituiu a república, em 1889, foi uma retaliação dos escravocratas pelo fato da monarquia ter libertado os escravos no ano anterior. ${ }^{30}$ Pelo alvitre de Teresa Malatian Roy (2001:57), a crítica que Veiga dos Santos fazia ao sistema político vigente era no sentido de responsabilizar a República pela "situação de penúria dos negros".

Na concepção deste dirigente negro, a república brasileira tem uma espécie de índole escravocrata, além de que "divide" os "irmãos da mesma Raça", ${ }^{31}$ ao passo que a monarquia teria um valor providencial para o negro. Santos foi uma das primeiras lideranças negras a exigir que a república implementasse políticas públicas específicas de "educação moral e profissional"32 em benefício da população negra. Seria uma medida reparatória ao estado de suposto entorpecimento cultural a que foi submetida tal população no sistema escravista no Brasil. Ele defendia, em perspectiva mais ampla, uma via integracionista de combate ao racismo.

Como informa Pinto (1993:137), o patrianovismo de Veiga dos Santos preconizava a monarquia com um imperador responsável, que reinasse e governasse; um estado imperial orgânico de base municipal (corporativa),

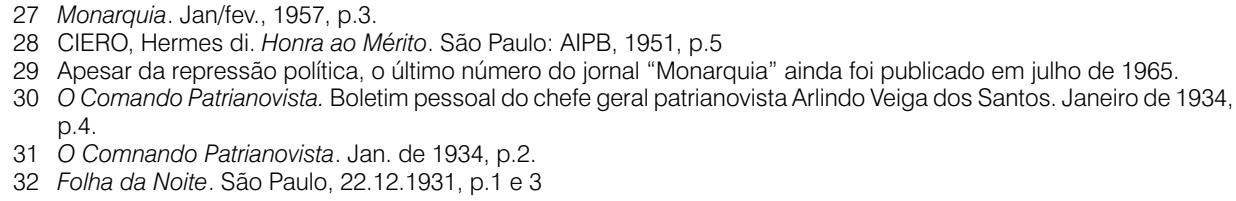


um estado em que a representação se faz pela família e pelo trabalho. Por intermédio dos sindicatos profissionais e das corporações sociais, econômicas e culturais (as universidades, as classes armadas, o clero, o magistério, as profissões liberais, a agricultura, a indústria, o comércio), dentro de uma instância maior, a orgânica imperial, garantiria-se o bem estar da nação. Seria justamente esse estado orgânico-sindicalista o único capaz de considerar a "gente negra" como uma realidade nacional, de forma igualitária aos outros grupos étnicos.

Arlindo Veiga dos Santos preconizava a unidade da "raça brasileira", pois entendia que o país não tinha uma raça completamente definida. Para tanto, apontava a necessidade de "acabar com os quistos estrangeiros dentro do Brasil e impor um critério novo em defesa da Velha-Raça em que hão de diluir-se os novos integrados (filhos de estrangeiros)". ${ }^{33}$

Combateu veementemente o mito da raça pura, do "branco puro sangue", como escreveu em um panfleto. Em seus textos, fazia questão de ressaltar que o cruzamento racial era processo inerente a todos os povos, por isso não havia justificativa para a desqualificação do mestiço brasileiro. Cumpre assinalar que essa tomada de posição a favor dos mestiços era uma resposta às explicações científicas da época segundo as quais mestiços e caboclos constituíam uma raça inferior, incapazes de alcançar o grau mais alto da civilização. Em vez dessa explicação do racismo científico, Veiga dos Santos entendia que o cruzamento das três matrizes étnicas (indígena, lusitana e africana) resultaria na formação da "raça brasileira", que pertenceria à Grande Raça (Malatian Roy,1978:83). Em alguns documentos, defendeu inclusive a criação do "Dia da Raça".

$\mathrm{Na}$ sua avaliação, a raça brasileira estava sendo desprezada pelos governos "desmoralizantes" da República. Por isso, criticou visceralmente a imigração européia promovida no final do XIX e início do XX. Para Veiga dos Santos, a imigração em massa de brancos era um processo "acatólico", de uma "eugenia judia", expressão de um governo preocupado com a "arianização geral da nação brasileira".

Contudo, não podemos cometer equívocos interpretativos: Arlindo Veiga dos Santos não desenvolve, em seus escritos, um projeto de negritude. Como argumenta Clóvis Moura (1994:195), sua proposta consiste, fundamentalmente, na "formação de uma nação na qual essas etnias iniciais - português, índio e negro - construiriam as matrizes que dariam os alicerces fundamentais dessa triangulação étnica desembocando em uma raça brasileira morena".

A despeito da sua produção teórica jamais ter sido voltada para pensar centralmente o problema do negro, Arlindo Veiga dos Santos acreditava,

33 O Comando Patrianovista. Dezembro de 1933, p.5. 
sub-repticiamente, que a eliminação do racismo iria acontecer no bojo da construção do modelo de sociedade patrianovista. Clóvis Moura (1994:195) é incisivo: "Não podemos ver no seu pensamento um direcionamento radical reivindicativo do negro", mas uma proposta de nacionalismo capaz de diluir o racismo progressivamente, "à medida que os valores conservadores — catolicismo, monarquismo e autoritarismo — se afirmassem como valores politicamente dominantes".

\section{7. À guisa de considerações finais}

No balanço de Clóvis Moura (1994:195), a trajetória política e ideológica de Arlindo Veiga dos Santos é um exemplo emblemático da consciência dividida da intelectualidade negra brasileira:

se horizontalmente ele tem uma mensagem étnica de protesto, ou de contestação à situação do negro no Brasil, verticalmente a sua vivência reproduz os padrões e valores da civilização, da cultura e dos postulados religiosos, políticos e ideológicos dos brancos. Em última instância, tem a personalidade dividida, porque se de um lado protesta com ela, de outro é um dominado subliminarmente pela cultura do dominador". Porém, para compreendermos plenamente as contradições desse intelectual negro, precisamos adicionar uma outra variável no balanço de Clóvis Moura: a tradição de uma gama de negros e negras, no regime republicano, apoiarem de maneira patente ou latente a monarquia no Brasil. Mas, afinal, como se operou historicamente esse processo ? Como foi possível uma liderança negra, com discurso extremamente virulento e bizarro de denúncia, muitas vezes vazia do sistema político vigente, pelo menos na década de 1930, ter causado em alguma medida impacto na população negra organizada? (Clóvis Moura, 1994:195)

Em 1889, a monarquia foi derrubada provavelmente quando atingiu seu mais alto grau de popularidade entre a plebe negra e mestiça do país (Carvalho,1987:9; Chalhoub,1990:179). A admiração dos negros e das camadas populares, de um modo geral, se dirigia não só ao Imperador D. Pedro II, mas também à sua filha, a princesa Isabel, considerada a salvadora da "raça negra".

Após a abolição da escravatura, surgiu sob a inspiração de José do Patrocínio - abolicionista e liderança negra da época — a famigerada Guarda Negra, uma organização composta por negros libertos e capoeiras que, para demonstrar gratidão à princesa Isabel e à monarquia, reprimia violentamente todas manifestações públicas contrárias ao Império e sobretudo às atividades do Partido Republicano. Em São Paulo, o jornal A Redempção, ligado à organização abolicionista caifazes, declarava seu apoio "irrestrito" tanto à "Princesa Regente" como à Guarda Negra, cujas ações geravam um clima de pânico na elite branca republicana (Schwarcz,1987:243). Não obstante, com a proclamação da república, em 15 de novembro 1889, a 
Guarda Negra foi dissolvida e, sintomaticamente, outro dirigente negro monarquista, André Rebouças, parte para o exílio em Portugal, em solidariedade à família real. Já o líder negro José do Patrocínio, permanece no Brasil e adere por alguns anos ao "isabelismo".

Nos seus primeiros anos de vida, a república continuou sofrendo oposição de diversos setores políticos, dentre os quais de grupos monarquistas, que buscavam capitanear todo descontentamento popular frente aos primeiros governos republicanos (Janotti,1986). Entre os negros, esse processo não foi diferente, por exemplo, Lima Barreto - o mais popular romancista do Rio de Janeiro - alimentava verdadeira ojeriza pela República e não ocultava sua simpatia pela Monarquia (Carvalho,1987:30). Esta significativa rejeição do meio negro aconteceu, desconfiamos, porque os consecutivos governos da Primeira República levaram a cabo um projeto "civilizatório" de branqueamento do país, adotaram uma série de medidas sanitárias antipopulares e autoritárias de "limpeza" étnica do espaço urbano das grandes capitais, mas, principalmente, pelo fato do regime republicando ter abandonado a massa de ex-escravos e de seus descendentes à sua própria sorte, não lhes garantindo os plenos direitos no exercício da cidadania (como emprego, moradia, terra, educação, participação política e liberdade de manifestação cultural ou religiosa). As autoridades policiais reprimiam rispidamente as práticas do jogo do bicho, da capoeira e de qualquer religiosidade de matriz africana. Portanto, a república, no limite, teve uma orientação discriminatória e promoveu a marginalização do povo negro, o que gerou sérios ressentimentos e, porque não dizer, o fetiche nostálgico da ordem anterior. ${ }^{34}$

Em São Paulo, algumas frações do incipiente movimento negro organizado que surgiu no início do século XX também se alinhavam em prol do ideal monarquista. Em diversos artigos dos jornais da imprensa negra, é possível identificar um discurso explícito ou implícito de apologia desse regime político. ${ }^{35} \mathrm{Em}$ praticamente todo 13 de Maio, estes jornais publicavam editoriais ou matérias idolatrando a figura da princesa Isabel, que recebeu o epíteto de "a redentora". ${ }^{36}$ Encontramos, outrossim, artigos de enaltecimento a D. Pedro II. ${ }^{37}$ Ainda no jornal Progresso ${ }^{38}$ encontramos a notícia de lançamento da revista Pátria Nova, ligado ao Centro Monarquista de Cultura Social e Polícia, que, no seu primeiro número, trazia uma

\footnotetext{
34 Florestan Fernandes (1978:64) recolheu, na década de 1950, o seguinte depoimento de um respeitado intelectual do meio negro: "a monarquia foi melhor para os negros. Apesar das dificuldades que existiam à ascensão do negro, por causa da vigência da escravidão, durante a monarquia sobressaíram várias personalidades negras. (...) Em todo período republicano, não se sobressaiu nenhum grande homem negro. Os que são apontados, se fizeram no tempo da monarquia".

35 O Clarim d'Alvorada. São Paulo, 13.05.1927, p.3.

36 Progresso. São Paulo, 15.11.1928, p.3.

37 Progresso. São Paulo, dezembro de 1930, p.2.

38 Progresso. São Paulo, 31.19.1929, p.5.
}

\section{4}


homenagem a comemoração do $20^{\circ}$ aniversário de D. Pedro Henrique de Orleans e Bragança, herdeiro presuntivo do trono brasileiro. Como escreve George Andrews,

\begin{abstract}
ainda na década de 1930 a imprensa negra de São Paulo trazia notícias de clubes e organizações sociais monarquistas, como por exemplo: Gentileza (Progresso. São Paulo, 24 de fevereiro de 1929, p.2) e D. Pedro Henrique (Progresso. São Paulo, 28 de setembro de 1930, p.1). Quando a escola de samba Vai-Vai foi organizada em 1930, optou por colocar uma coroa no centro da sua bandeira com homenagem à monarquia. (George Andrews, 1991:43)
\end{abstract}

Portanto, quando Arlindo Veiga dos Santos entrou no cenário histórico e lançou publicamente suas idéias, na década de 1920, já havia, seja um sentimento difuso ou "caldo de cultura" anti-republicano, seja uma sólida tradição de setores da população negra no cultivo de uma representação positiva do Império e, no limite, um fascínio pela restauração da monarquia no país. Nesse sentido, Veiga dos Santos não inovou, mas apenas deu continuidade a essa tradição, que, por sinal, se estende até os dias de hoje. Afinal, não podemos esquecer que no plebiscito de 1993, para decidir qual era a melhor forma de governo, alguns expoentes da comunidade negra no país fizeram campanha publicitária em prol da monarquia, como a atriz Zezé Mota, os cantores Jards Macalé, Sandra de Sá e a sambista Dona Zica, então liderança do Grêmio Recreativo Escola de Samba Estação Primeira da Manqueira. Da mesma maneira, é importante assinalar que algumas instituições constituídas apenas por negros, como a Imperial Irmandade Nossa Senhora do Rosário e São Benedito dos Homens Pretos, do Rio de Janeiro, continuam reverenciando a memória da Princesa Isabel e mantendo fidelidade à Casa Imperial. No jornal da referida entidade, Redenção, de setembro e outubro de 1999, alardeia-se a homenagem prestada a Dna. Isabel de Orleans de Bragança, bisneta da Princesa Isabel, em cerimônia realizada na sede da irmandade, comemorativa do 13 de Maio, dia da abolição da escravatura.

Assim, não seria possível sustentar que as palavras de ordem de Arlindo Veiga dos Santos - emprestadas como subtítulo deste artigo - permanecem vivas no imaginário de muitos negros e negras brasileiros?

Viva a nova monarquia brasileira!

Viva Dom Pedro III !39

39 SANTOS, Arlindo Veiga dos. O que é Patrianovismo. s/d, p.2 


\section{REFERÊNCIAS BIBLIOGRÁFICAS}

ANDREWS, George Reid. Negros e brancos em São Paulo(1888-1988). Bauru: Edusc, 1998.

O protesto político negro em São Paulo (1888-1988). Estudos Afro-Asiáticos, (21):2748, dezembro de 1991.

BARBOSA, Márcio (Org.). Frente Negra Brasileira: Depoimentos. São Paulo: Quilombhoje, 1998.

BARBOSA, Wilson do Nascimento. O Problema do Negro na História do Brasil. Salvador: Conferência na Universidade Federal da Bahia, 1985, mimeo.

CARONE, Edgard. A República Nova (1930-1937). São Paulo: DIFEL, 1974.

CARVALHO, José Murilo de. Os bestializados: o Rio de Janeiro e a República que não foi. São Paulo: Companhia das Letras, 1987.

CARONE, Edgard. A República Nova (1930-1937). São Paulo: Difel, 1982.

CHALHOUB, Sidney. Visões da liberdade: uma história das últimas décadas da escravidão na Corte. São Paulo: Companhia das Letras, 1990.

DOMINGUES, Petrônio. Uma história não contada. Negro, racismo e branqueamento em São Paulo no pós-abolição. São Paulo: Ed. Senac, 2004.

A insurgência de ébano. A história da Frente Negra Brasileira (1931-1937). São Paulo: Tese de Doutorado, FFLCH/USP, 2005.

FERNANDES, Florestan. A integração do negro na sociedade de classes. $3^{\mathrm{a}}$ ed. São Paulo: Ática, 1978.

O negro no mundo dos brancos. São Paulo: Difel, 1972.

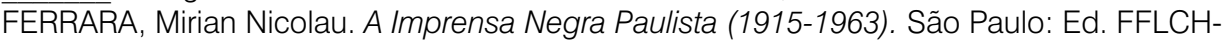
USP, Coleção Antropologia, n.13, 1986.

JANOTTI, Maria de Lourdes Mônaco. Os subversivos da República. São Paulo: Brasiliense, 1986.

LEITE, José Correia. E disse o velho militante José Correia Leite: depoimentos e artigos (Cuti, organização e textos). São Paulo: Secretaria Municipal de Cultura, 1992.

MOURA, Clóvis. Dialética radical do Brasil negro. São Paulo: Editora Anita, 1994.

Sociologia do negro brasileiro. São Paulo: Ática, 1988.

História do negro brasileiro. São Paulo: Ática, 1987.

O negro, de bom escravo a mau cidadão? Rio de Janeiro: Conquista, 1977.

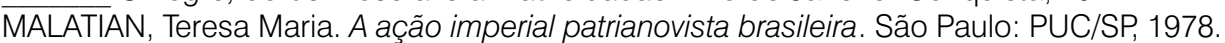
(Dissertação de Mestrado)

Império e Missão. Um novo monarquismo brasileiro. São Paulo: Companhia Editora Nacional, 2001.

MOREIRA, Renato Jardim \& Leite, José Correia. Movimentos sociais no meio negro. São Paulo: mimeogr, s/d.

PINTO, Regina Pahim. O movimento negro em São Paulo: luta e identidade. São Paulo: FFLCH/USP, 1993. (Tese de Doutorado)

SANTOS, Arlindo Veiga dos. Contra a Corrente. Edição Patrianova. São Paulo, 1931.

Um pequeno histórico da Pátria-Nova. O comando Patrianovista. Boletim Pessoal do Chefe Geral Patrianovista. São Paulo, nº.1, dez.,1933.

Para a Ordem Nova. São Paulo: ed. Pátria-Nova, 1933.

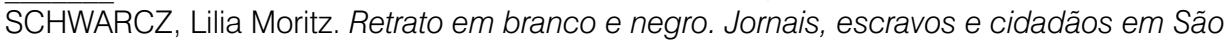
Paulo no final do século XIX. São Paulo: Companhia das Letras, 1987.

TRINDADE, Hélgio. Integralismo. O fascismo brasileiro na década de 30. São Paulo/Porto Alegre, Difel/UFRGS, 1974. 